\title{
Basic psychological needs in relationships with parents and best friend and identity statuses among Turkish emerging adults
}

\author{
Pınar Erçelik ${ }^{1}$ (D) - Ayfer Dost-Gözkan ${ }^{1}$ (D) \\ (C) Springer Science+Business Media, LLC, part of Springer Nature 2020
}

\begin{abstract}
The present study a) compared emerging adults' perceived basic psychological needs (autonomy, relatedness, competence) satisfaction (BPNS) in their relationships with their parents and best friends b) examined the links between BPNS and identity statuses (achievement, moratorium, foreclosure, diffusion) c) examined the links between each psychological need and identity statuses in each relationship. A total of 396 emerging adults participated in the study. The perceived BPNS in one's relationship with his/her mother and one's best friend was found to be higher than the BPNS with one's father; further, the BPNS in one's relationship with one's best friend was higher than that in one's relationship with one's mother - but only among females. Structural equation modeling (SEM), conducted to examine the links between BPNS and identity statuses, showed that the BPNS in participants' relationship with their friend was positively linked with achievement and inversely linked with moratorium, foreclosure, and diffusion. The BPNS in one's relationship with one's mother was positively linked with achievement and negatively linked with moratorium. Higher BPNS in one's relationship with ones's father was linked only with higher foreclosure. BPNS in their relationships with best friends predicted four identity statuses. Competence was linked positively with identity achievement and negatively linked with the other identity statuses across the three relationships. Overall, findings underlined the importance of close friendships in the pursuit of identity and the satisfaction of the basic need for competence across the three relationships.
\end{abstract}

Keywords Emerging adulthood $\cdot$ Basic psychological needs $\cdot$ Identity statuses $\cdot$ Self-determination theory $\cdot$ Parent-youth relationships

Until recently, identity development has been considered a primary developmental task undertaken in adolescence. Erikson (1956), defining adolescence as the transition period from childhood to adulthood, proposed that young people explore various identities and commit to the appropriate ones during this period. The proliferation of life choices in industrialised societies and an increase in the average age of transitioning to adult roles (i.e., having a steady job, starting a family, and having children), however, has prolonged the pursuit of identity and pushed identity commitment to the late twenties (Arnett 2000; Côté 2009; Luyckx et al. 2008; Schwartz et al. 2013). Some scholars (e.g., Ryan and Deci 2017) argue that the task of

Ayfer Dost-Gözkan

ayfer.dost@ozyegin.edu.tr

Pınar Erçelik

pinar.ercelik@gmail.com

1 Department of Psychology, Ozyegin University, Istanbul, Turkey defining oneself is more demanding today as compared to previous generations, because current young people must choose among a wide range of identity alternatives - an activity that exerts a psychological burden for them.

Given this developmental challenge, it is worth examining the facilitators of identity formation. Relying on the selfdetermination theory (SDT), the present study aimed to examine the relationships between the gratification of basic psychological needs (autonomy, relatedness, and competence) that emerging adults perceive in their close relationships (i.e., with their mother, father, and best friend) and their identity statuses (achievement, moratorium, foreclosure, and diffusion). The present study also aimed to examine the extent to which young people perceive basic psychological needs gratification (BPNS) within these three relationships, in comparison to each other, in order to understand the relative significance of each relationship's context.

The relationship with parents as well as with friends play a crucial role in the lives of emerging adults (Demir 2010). Previous research focused on research with mothers, fathers 
or friends, yet research focusing simultaneously on multiple close relationships is rare. However, concurrent examination of the multiple close relationships is a promising approach to understand their relative role in outcome variables (Demir 2010). Therefore, the present research focused on three important close relationships in the lives of emerging adults (i.e., mother, father, and the best friend).

\section{Identity Formation and Basic Psychological Needs}

James Marcia (1966) described the processes through which individuals form an identity as exploration and commitment processes; he also proposed four identity statuses based on the combinations of these two processes. The four identity statuses are called identity achievement, moratorium, foreclosure, and identity diffusion. Identity achievement involves exploration of different identity options is followed by committing to the most appropriate one. Moratorium involves attempts to explore various identity options without committing to any of them. Foreclosure refers to the process of committing to an identity that is readily available to the individual or decided by others without the individual going through a process of exploration. Finally, the identity diffusion status involves neither a search for an identity nor commitment to any of the identity options. Achievement and moratorium statuses which, by definition, involve exploration - have been considered to be a more mature condition than foreclosure or identity diffusion, in which exploration is not the predominant characteristic (Kroger 2007). Empirical research (Berzonsky and Adams 1999; Kumru and Thompson 2003; Luyckx et al. 2009) has provided support for this claim. Such studies have found that achievement and moratorium were associated with positive psychological outcomes such as high self-esteem, a sense of autonomy, good problem-solving skills, psychological well-being, and less self-monitoring.

The relationship between the identity achievement status and positive psychological outcomes raises the question of which other variables might be related to (i.e., provide support for) the healthy pursuit of one's identity. In the process of forming an identity, individuals are expected to search for and explore a range of identity options (Erikson 1956; Kroger and Marcia 2011; Marcia 1966). The assumptions of SDT (Deci and Ryan 2000; Ryan and Deci 2017) regarding human nature and development have drawn attention to fundamental psychological needs that are necessary for flourishing across various domains, including identity formation. One of the mini-theories of SDT, the basic psychological needs theory (BPNT), suggests that provision of the basic psychological needs of autonomy, relatedness, and competence intrinsically motivate individuals to engage in activities that will positively contribute to their pursuit of identity (Ryan and Deci 2017).
The need for autonomy is the need to manage one's life and behaviours by his/her volition. Autonomous individuals respond to their environment and behave in accordance with their internalised values. The need for relatedness is defined as the need for belonging and being in close and supportive relationships. Finally, the need for competence pertains to the feeling within an individual that he/she has the knowledge, skills, and/or capacity to perform well on various tasks, to learn new things and, as well, to overcome difficulties (Ryan and Deci 2000, 2017).

BPNS is conducive to healthy development and, as well, an increase in subjective well-being (Deci and Ryan 2000). Indeed, research (Deci et al. 2006) has found BPNS to be positively linked with a positive emotional state while it was negatively linked to negative emotions. BPNS has also been found to be positively associated with high academic achievement and job motivation (Deci et al. 2001; Faye and Sharpe 2008). Few studies, however, examined the connection between BPNS and identity formation; and they found that needs-gratification was associated with positive identity formation (Faye and Sharpe 2008; Luyckx et al. 2009). The present study aimed to contribute to the literature by examining the links between BPNS in three important close relationships and identity statuses among emerging adults in a sociohistorically heterogeneous culture in which identity synthesis may require hard work and is demanding.

\section{The Relationship Contexts and BPNS}

The basic psychological needs of the individual can be met by others with whom the person is in a socio-emotionally significant relationship. Thus, the gratification of one's needs always takes place in a social-relational context. Various studies have investigated how different close relational contexts differ in the extent to which they meet a person's basic psychological needs. For example, La Guardia et al. (2000) compared the level of BPNS young people perceived in their relationships with their parents, best friends, and romantic partners and found that the participants perceived highest levels of BPNS in their relationship with their close friends ( $\mathrm{La}$ Guardia et al. 2000). In another study conducted with emerging adults, the psychological needs were found to be mostly met, in order, by close friends, romantic friends, and parents (Ryan et al. 2005). The same study found that friendship support was the strongest predictor in their model, which examined the links between psychological need gratification and secure attachment.

Both theory and research emphasized the continuity of relationship with parents and their significance in transition from adolescence to adulthood (Aquilino 1997, Aquilino 2006) and that positive relationship with parents is essential for flourishing in emerging adulthood as well (Padilla-Walker 
et al. 2017). Research generally examines the role of parents without distinguishing between differential impact of mother and fathers. Limited number of research has examined the role of maternal and paternal support in emerging adulthood. For example, the quality of the relationship with mother was found to be linked with a variety of positive outcomes (e.g., prosocial behavior and religious faith) (Barry et al. 2012; Barry et al. 2008; Demir 2010). Very few studies examined the role of fathers as compared to mothers in the lives of emerging adults (for a discussion, see Padilla-Walker et al. 2017). In a study, positive relationship with both one's father and mother individually predicted well-being (e.g., happiness, life satisfaction, and lower psychological distress) of emerging adults (Amato 1994). Amato (1994) underlined the importance of fathers as figures who have unique role in the wellbeing of their adult children.

Demir (2010) examined the relationship quality with mother, father and best friend simultaneously and found that only the mother and best friend relationship quality were linked to happiness, whereas relationship quality with father did not contribute to happiness in emerging adults. In line with the previous literature which state that relationship with mother has stronger impact on well-being as compared to the relationship with father (Field et al. 1995), Demir (2010) concludes that although there are changes in the structure of relationship with parents during emerging adulthood, the relationship with mother continues to be influential on the well-being and happiness of their adult children.

In the literature, friendships have been found to become increasingly important for young people starting from the teenage years (Scholte and Van Aken 2008). Positive friendships have been shown to be associated with positive outcomes throughout life (Hartup and Stevens 1997). Indeed, Hartup and Stevens (1997) state that having supportive and socially competent friends is like having money in the bank: they are the "social capitals" in our lives. Friendships can especially be important sources of support during emerging adulthood as young people navigate through challenging developmental tasks such as identity formation (Barry et al. 2016). Research showed that friendships are important source of happiness during emerging adulthood as friends gratify basic psychological needs (Demir et al. 2007; Demir et al. 2007).

Muzafer Sherif and colleagues' explanations of natural group formation can be utilised to explain why friendships gain importance during transition to adulthood (for a discussion, see Dost-Gözkan 2015). Muzafer Sherif and colleagues (Sherif and Cantril 1947; Sherif and Sherif 1956; p. 65) underlined that in Western industrial societies, the transition from childhood to adult roles can take a long time. During this protracted period, young people often find themselves betwixt and between because taking part in the adult world is getting increasingly more complex and more demanding, in comparison to previous stages of development. Sherif and Sherif (1965), in this regard, note that being betwixt and between is not 'a comfortable experience' for an individual: 'the more the period is prolonged without establishing stable bearings, the more painful it becomes' (p. 4.). This experience of being betwixt and between not only includes being between childhood and adulthood in an extended time window, but also straddling various reference frames, worldviews, and alternative identities. Sherif and Sherif (1965) further argue that, in the pursuit of redefining one's self, the guidelines or 'anchors' the adult world provides for the young are not satisfactory. This can cause a divergence of perspectives in approaching a range of daily issues. This is where the world of peers and friends comes in, providing an essential reference group and meaningful frames of reference (Sherif and Cantril 1947). During this time, a youngster will turn to friends because they have similar concerns and 'they [peers] become his reference sets in sizing up his own problems, his own strivings, and his own ambitions since they see each other "in the same boat"' (Sherif and Sherif 1965, p. 4). These researchers regarded youth groups and friendships as examples of informal groups whose members, upon experiencing similar problems for a long time, try to find a common platform for sharing their views and seeking a solution for those issues.

In transition to adulthood, both parents and peers are important reference groups, providing an important mainstay for their pursuit of identity (Dost-Gözkan 2015). The present study, therefore, focused on an examination of the relations between the perceived BPNS and identity statuses within both the parental and best friend relational contexts.

\section{Emerging Adulthood in the Turkish Context}

Jeffrey Arnett defined the age range between 18 and 29 as a new developmental stage, which he termed emerging adulthood (Arnett 2000; Arnett et al. 2014). During this phase, although youngsters are more independent of their parents (compared to their teenage years), they do not fully assume adulthood responsibilities (Arnett 2000). Developmentally, the emerging adulthood stage is characterised by a search for identity within various life domains (e.g., world view, occupation, relationships, romantic partners, religion). It is also a time of uncertainty, with a strong focus on oneself and a feeling of being neither an adult nor an adolescent (Arnett 2000, 2004). Until the end of their twenties, Arnett states, emerging adults have occasion to make key decisions in important domains (e.g., family, occupation, and worldview) while, at the same time, just beginning to make identity commitments and consolidations.

Arnett claims that this developmental phase is not universally valid but defines only experiences of young people in industrialised societies. As a response to the question of the 
extent emerging adulthood is experienced by young people around the world, an important line of research examined whether emerging adulthood is experienced in Turkey. Researchers found that college students do possess the characteristics of the developmental period of emergent adulthood (eg. Atak 2005; Atak and Çok 2008; Morsünbül 2013). Morsünbül (2013) further elaborated this question and conducted a study with college students and non-student of adults (ages between 19 and 25) to examine if both groups possess the characteristics of emerging adulthood. The findings showed that emerging adulthood period defines only experiences of college students and does not reflect experiences of young adults who completed their college education and young people who started to work right after graduation from high-school.

In their work with young people between the ages of 19 and 26, Atak and Taștan (2012) showed that variables such as beliefs about being an adult, working, having a college degree predicted experience of agency (the ability to direct their own behavior). These studies are valuable in terms of portraying the profile of emergent adulthood in Turkey.

\section{Research on Identity Statuses in the Turkish Context}

Some researchers (Arnett 2000; Côté 2006) have suggested that the process of exploring various identities and committing to same - as a developmental endeavour - is increasingly experienced when a person is in his/her twenties. Muzafer Sherif's (Sherif and Sherif 1956, 1965) remarks on the challenge of the transition to adulthood in the 1940s and 1950s has become even more evident today: The search and the consolidation of identity is even more prolonged as compared to previous generations. In addition, for today's youth, life offers more choices and alternative identities in many areas; moreover, the business world expects increasingly more knowledge and skills today than it expected in previous decades (Ryan and Deci 2003).

Muzafer and Carolyn Sherif (Sherif and Sherif 1956) stated that, in societies undergoing transition, young people are confronted with conflicting world views and life choices. For this reason, the authors argue that young people should spend more time and effort working at achieving identity synthesis. The modern Turkish society, as a result of its sociopolitical history, comprises a heterogeneity of influences including collectivism and, as well, both Islamic and Western-secular values (Nauck and Klaus 2008). Although this diversity allows for the synthesis of a broad range of ideas, cultural perspectives and norms, it also can present contradictory values, making their evaluation and application - and with that, the identity synthesis process itself - more challenging (Dost-Gözkan and Wiium in press; Morsünbül et al. 2015). In this respect, it is worthwhile to investigate the factors that might facilitate identity formation and test the BPNT in a non-Western cultural context.

There has been some research on identity statuses in Turkey since the adaptation of the Ego Identity Status Scale by Oskay (1998). In recent years, more recent identity measures were validated in Turkish including the Dimensions of Identity Development Scale (Luyckx et al. 2008; Morsünbül and Çok 2014) and Utrecht-Management of Identity Commitments Scale (Crocetti et al. 2008; Crocetti et al. 2015). These measures provided evidence that exploration and commitment dimensions of identity processes are valid processes that can capture the identity formation experiences of Turkish young people.

Until recent years, identity research conducted in Turkey focused predominantly on adolescent samples (Atak 2011). Identity research has increasingly begun to focus on emerging adulthood in the last 10 years. For example, Atak et al. (2012) examined the relationship between types of individuation and identity statuses in emerging adulthood found that young people experience both types of developing individuation (taking responsibility for one's own life) and default individuation (low agency), and that developmental individualization is linked with more successful identity statuses, whereas standard individuation is linked with lower identity statuses (Atak et al. 2012).

Ahmed (2019) examined the links between emerging adulthood characteristics and religious identity and found that emerging adulthood characteristics were positively linked with moratorium while they were negatively linked with foreclosure. Ergin (2015) examined the relationships between identity statuses and coping strategies and found that identity achievement was positively linked with problemfocused and indirect coping strategy, and foreclosure was linked with emotion-focused coping strategy. Ilhan and Özdemir (2012) examined the links between attachment styles and identity statuses and found that secure attachment was positively linked with identity achievement while insecure attachment was positively linked with moratorium and identity diffusion. These research focus more on the outcome-wise correlates of identity statuses; the present research aims to examine potential contributors of identity statuses.

\section{The Present Study}

In view of the literature reviewed above, the present study has three research aims.

1. To compare the level of BPNS emerging adults perceive in their relationships with their mother, father and the best friends.

Hypothesis 1: The perceived BPNS in one's relationship with his/her best friend will be higher than that perceived 
in one's relationship with his/her mother and father. Also, comparing the relationship with one's mother to that with one's father, BPNS perceived from one's mother will be higher than that from the father.

2. To examine the links between BPNS that emerging adults perceive in their relationships with their mother, father, and their best friends, and identity statuses

Hypothesis 2. BPNS in each relationship (mother, father, best friend) will be positively linked to identity achievement and moratorium and negatively linked to foreclosure and identity diffusion.

3. To examine the links between each of the basic psychological needs (autonomy, relatedness, competence) and identity statuses in each close relationship, 3) the extent emerging adults

Hypothesis 3. From SDT perspective each need is expected to be linked positively to identity achievement and moratorium, and negatively to foreclosure and identity diffusion. However, the relative strength of each need when put in the equation together cannot be derived from the theory. Therefore, the third research aim also has an exploratory intent.

\section{Method}

\section{Participants}

The sample consisted of 396 college students in a metropolitan city (Istanbul) in Turkey. The majority of the participants $(73.4 \% ; N=292)$ were female and $26.1 \%(N=$ $104)$ of the participants were male. Two participants did not report their sex. The participants' mean age was 21.71 $(S D=1.90)$, ranging between 18 and 26. Female participants, on average, were 21.54 years old $(S D=1.90)$, while male participants, on average, were $22.21(S D=1.8)$ years old. Univariate analysis of variance showed that this age difference was statistically significant, $F(1,391)=9.23$, $p=.003, \eta=.002$. The mean of the educational level of the participants' mothers was $4.89(S D=1.36)$, while that of the fathers was $5.09(S D=1.20)$. The parental socioeconomic status (SES) was calculated from the average of the education levels of the parents $(M=4.71, S D=1.20)$. Parental education ranges between 1 and $5(1=$ primary school, 2 = middle school, 3 = high school, 4 = vocational college, 5 = undergraduate degree). Univariate analysis of variance showed that parental SES was not statistically different between male and female participants.
Two participants did not report their major. Majority of the participants who reported their majors were Psychology students $(47.80 \%)$, followed by Engineering (17.76\%), Economy/Finance/Business Administration (14.56\%), Fine Arts $(4.96 \%)$, Politics $(3.02 \%)$, and Philosophy students $(3.02 \%)$. The percentage of remaining participants $(8.88 \%)$ were from a variety of majors including Counselling, Law, Architecture, Media, Aviation, Gastronomy and Culinary Arts, Agriculture, Medicine, Hotel Management, History, Education, Politics, Literature, and Physics/Chemistry (the percentages were within the range of $1.92 \%$ and $0.27 \%$ ).

\section{Measures}

Demographic Form The demographic questionnaire asked participants' age and sex and their parents' educational attainment.

Basic Psychological Needs Scale (La Guardia et al. 2000) This questionnaire consists of 9 items rated on 7-point scale. The present study used a 5 -point scale ( $1=$ totally disagree; $5=$ totally agree). The scale assesses the extent to which an individual perceives BPNS in a specific relationship. There are 3 items for each basic need. Sample items are: 'When I am with ..., I feel free to be who I am' for autonomy; 'when I am with ..., I feel loved and cared about' for relatedness; and 'when I am with ..., I feel like a competent person" for competence. The average of all items indicates the level of gratification of basic needs in a given relationship. The participants rated their relationships with their father, their mother and their best friend using this scale. The Turkish validation of this scale was conducted by the second author in a sample of 1367 adolescents (age range $=11-19$ ). The confirmatory factor analysis indicated a good fit between the model and the data, $\chi^{2}=5.19, d f=5, p=.39 ;$ CFI $=1 ;$ TLI $=1$; RMSEA $=.01$. In the validation study, reliability coefficients were $.81, .83$ and .78 for the mother, the father and the best friend, respectively. In the present sample, the reliability coefficients were. $86, .88$, and .80 , for the mother, the father, and the best friend versions, respectively. For mother, father and the best friend forms, respectively, the reliability coefficients for autonomy subscale were $.64, .73$, and .51 , for relatedness subscale .70, .82 and .62, and for competence, .70, .76, and .71.

Extended Objective Ego Identity Status Scale (Bennion and Adams 1986) assesses the identity status of individuals aged from 13 to 30 years. The scale is composed of two main identity categories: ideological identity and interpersonal identity; each consists of 32 items rated on a 6-point Likert scale ( $1=$ strongly agree; $6=$ strongly disagree). Each of these subscales consists of 4 subcategories. Ideological identity 
consists of items related to political, professional, religious, and philosophical domains and, as well, self-related explorations and commitments. Interpersonal identity includes items related to gender roles, lifestyle, leisure activities and interpersonal relationships. Items measure exploration and commitment in these subdomains and yield four identity statuses: achievement (e.g., 'I've had many different friendships and now I have a clear idea of what I look for in a friend'); moratorium (e.g., 'I'm still trying to decide how capable I am as a person and what work will be right for me'); foreclosure (e.g., 'My parents' views on life are good enough for me, I don't need anything else') and diffusion (e.g., 'Sometimes I join in leisure activities, but I really don't see a need to look for a particular activity to do regularly'). The scale was adapted to the Turkish language by Oskay (2008). In the present sample, the reliability coefficients were $.85, .78$, .94 , and .78 , for achievement, moratorium, foreclosure, and identity diffusion, respectively.

\section{Procedure}

Prior to data collection, approval for the investigation was obtained from the Ethics Committee of Ozyegin University. Participants filled out an anonymous survey administered via Qualtrics. At the beginning of the survey, informed consent was taken from the participants. They also were assured a) of anonymity and confidentiality and b) that participation in the study was voluntary and that they were free to quit if they did not wish answer the questions.

\section{Results}

\section{Descriptive Results}

The relationships among the variables, including the demographics of the participants, were first examined with bivariate correlations and (Table 1) partial correlations (Table 2). Age was negatively related with sex, indicating that female participants were younger than males. Age was also negatively linked with SES, BPNS in the relationship with one's mother, father, and best friend, and moratorium status. Sex was positively linked with BPNS in participants' relationship with their best friend, and identity achievement status, indicating that the female participants perceived a higher BPNS in their relationship with their best friend; also, they had higher scores on identity achievement and lower scores on foreclosure and diffusion, when compared to their male counterparts. Finally, as SES increased, BPNS in the relationship with father and foreclosure increased.

Both bivariate correlations and partial correlations (controlling for sex, age, and SES) indicated that BPNS in the participants' relationships with their mother, father and best friend were positively related to each other. BPNS was positively related to identity achievement and negatively related with moratorium and identity diffusion across the three relationships. BPNS in one's relationship with one's mother and with one's close friend was negatively linked with foreclosure.

Bivariate and partial correlations among the identity statuses indicated that identity achievement was negatively linked with foreclosure and diffusion. Moratorium and achievement were not significantly linked to each other, but moratorium was positively related to foreclosure and diffusion. Finally, foreclosure and diffusion were positively linked to each other.

\section{Hypothesis Testing}

Research Aim 1 In order to examine the extent emerging adults perceive similar or different basic psychological needs support in their relationships with their mother, father, and best friend, repeated measures multivariate analysis of variance (MANOVA) was conducted separately for the male and female participants. ${ }^{1}$ Here, the within-subject variable was the participant's reports of BPNS they perceived in their three close relationships (mother, father, and best friend). The results of the analyses conducted separately for men and women showed that multivariate effect was significant (Wilks lambda for women $=.73, F(2,268)=49.07, p<.001, \eta^{2}=.27$; Wilks lambda for men $\left.=.27, F(2,99)=18.31, p<.001, \eta^{2}=.27\right)$. Follow-up univariate analyses (ANOVAs) carried out separately for male and female groups showed that both female and male participants perceived more BPNS in their relationship with their mothers than they did in their relationships with their fathers (female participants: Mother $(M=4.34$, $S D=.04)$; Father $(M=3.93, S D=.05), F(1,270)=73.31$, $p<.001, \mathrm{\eta}^{2}=.21$; male participants: Mother $(M=4.24$, $S D=.06)$; Father $(M=3.89, S D=.08), F(1,100)=35.83, p$ $\left.<.001, \mathrm{n}^{2}=.26\right)$. For both female and male participants, perceived BPNS in their relationship with their best friend was higher than that which they perceived in their relationship with their father (female participants: Friends $(M=4.43$, $S D=.03)$; Father $(M=3.93, S D=.05), F(1,271=93.61$, $p<.001, \eta^{2}=.26$; male participants: Friend $(M=4.28$, $S D=.06)$; Father $(M=3.89, S D=.08), F(1,100)=27.04, p$ $\left.<.001, \mathrm{\eta}^{2}=.21\right)$. The comparison of perceived BPNS in the relationship with one's mother and one's best friend indicated that only female participants perceived their relationship with their best friend as more supportive $(M=4.43, S D=.03)$ than

\footnotetext{
${ }^{1}$ Mixed-design covariance analysis (ANCOVA) allows the examination of the basic needs support in the context of three relationships for the whole sample. However, entering age as a covariate in the analysis does not merely control the variance due to age between male and female groups; it also controls the variance among individuals within each gender group. In the statistics literature, this problem has been discussed earlier (Gilmore 2007). As a solution, separate ANOVAs were suggested for the groups. Based on this suggestion, multivariate variance analysis was conducted for male and female groups separately in the present study.
} 
Table 1 Bivariate correlations among the study variables

$\begin{array}{lllll}\text { Age } & \text { Sex } & \text { SES } & \begin{array}{l}\text { BPNS- } \\ \text { Mother }\end{array} & \begin{array}{l}\text { BPNS- } \\ \text { Father }\end{array}\end{array}$ BPNS-Best Friend Achievement Moratorium Foreclosure

\begin{tabular}{|c|c|c|c|c|c|c|c|c|c|}
\hline Sex $1=$ Male $; 2=$ Female & $-.15^{* *}$ & & & & & & & & \\
\hline SES & $-.17^{* *}$ & -.07 & & & & & & & \\
\hline BPNS-Mother & $-.11^{*}$ & .04 & -.04 & & & & & & \\
\hline BPNS-Father & $-.14^{* *}$ & .02 & $.10^{*}$ & $.59^{* * * *}$ & & & & & \\
\hline BPNS-Best Friend & $-.12^{*}$ & $.12^{*}$ & -.00 & $.58^{* * *}$ & $.43^{* * * *}$ & & & & \\
\hline Achievement & -.01 & $.13^{*}$ & -.02 & $.31^{* * * *}$ & $.20^{* * *}$ & $.36^{* * *}$ & & & \\
\hline Moratorium & $-.15^{* *}$ & .03 & .10 & $-.25^{* * *}$ & $-.14^{* *}$ & $-.24^{* * * *}$ & -.08 & & \\
\hline Foreclosure & -.07 & $.10^{*}$ & $.16^{* * *}$ & $-.13^{*}$ & .05 & $-.24^{* * * *}$ & $-.20^{* * *}$ & $33^{* * *}$ & \\
\hline Diffusion & -.03 & $.12^{*}$ & .07 & $-.20^{* * * *}$ & $-.12^{*}$ & $-.33^{* * * *}$ & $-.30^{* * * *}$ & $.51^{* * * *}$ & $.49^{* * * *}$ \\
\hline
\end{tabular}

BPNS means basic psychological needs satisfaction

$p^{*}<.05, p^{* *}<.01, p^{* * *}<.001$

their relationships with their mothers $(M=4.34, S D=.04), F$ $(1,273)=5.51, p<.001, \eta^{2}=.02$.

The between-subjects univariate analysis of covariance (ANCOVA), comparing female and male participants' perception of BPNS in their relationships with their mother, father, and best friend, indicated that there was sex difference only in BPNS perceived in their relationship with their best friend: Females reported higher friend support $(M=4.42$, $S D=.03)$, than did males $(M=4.27, S D=.06), F(1,375)=$ $4.29, p=.05, \eta^{2}=.01$.

Research Aim 2 In order to examine the relations between BPNS in the three relationship and four identity statuses, an SEM analysis was conducted using M Plus 7.4 (Muthén and Muthén 1998-2015; see Fig. 1). Participants' age, sex, and SES were included in the model as the control variables. The fit indices for the measurement model indicated a good fit between the model and the data: $\chi^{2}=183.42, d f=90, p$
$<.001, \chi^{2} / d f=2.38$, RMSEA $=.05[.04-.06]$, CFI $/$ TLI $=.97 / .96$.

The fit indices for the structural model also showed a good fit between the data and the model: $\chi^{2}=228.45, d f=121, p$ $<.001, \chi^{2} / d f=1.88$, RMSEA $=.05$ [.04-.06], CFI / TLI $=.97$ / .96. The examination of the path coefficients indicated that, BPNS in the relationship with one's mother was positively linked with identity achievement and negatively linked with moratorium. BPNS in the relationship with one's father was positively linked with foreclosure. Finally, BPNS in the relationship with one's best friend was positively linked with identity achievement, while it was negatively linked with foreclosure and identity diffusion.

Research Aim 3 In order to examine the relations between satisfaction of each need (autonomy, competence, and relatedness) and four identity statuses in each relationship separate SEM analysis for each close relationship was conducted using
Table 2 Partial correlations controlling for age, aex, and SES

\begin{tabular}{lccllll}
\hline & $\begin{array}{l}\text { BPNS- } \\
\text { Mother }\end{array}$ & $\begin{array}{l}\text { BPNS- } \\
\text { Father }\end{array}$ & $\begin{array}{l}\text { BPNS-Best } \\
\text { Friend }\end{array}$ & Achievement & Moratorium & Foreclosure \\
\hline BPNS-Father & $.58^{* * *}$ & & & & \\
BPNS-Best & $.61^{* * *}$ & $.42^{* * *}$ & & & \\
$\begin{array}{l}\text { Friend } \\
\text { Achievement }\end{array}$ & $.31^{* * *}$ & $.23^{* * *}$ & $.36^{* * *}$ & & \\
Moratorium & $-.23^{* * *}$ & $-.17^{* *}$ & $-.25^{* * *}$ & -.06 & $.26^{* *}$ & \\
Foreclosure & -.04 & .06 & $-.23^{* * *}$ & $-.16^{* *}$ & $.49^{* * *}$ & $.31^{* * * *}$ \\
Diffusion & $-.17^{* * *}$ & $-.14^{*}$ & $-.34^{* * *}$ & $-.29^{* * *}$ & & \\
\hline
\end{tabular}

BPNS means basic psychological needs satisfaction $p^{*}<.05, p^{* *}<.01, p^{* * *}<.001$ 
Fig. 1 Links between the basic psychological needs-gratification in the relationship with mother, father, and the best friend, and identity statuses. Note. BPNS means perceived basic psychological needs satisfaction. $p^{*}<.05, p^{* *}<.01, p^{* * *}<.001$

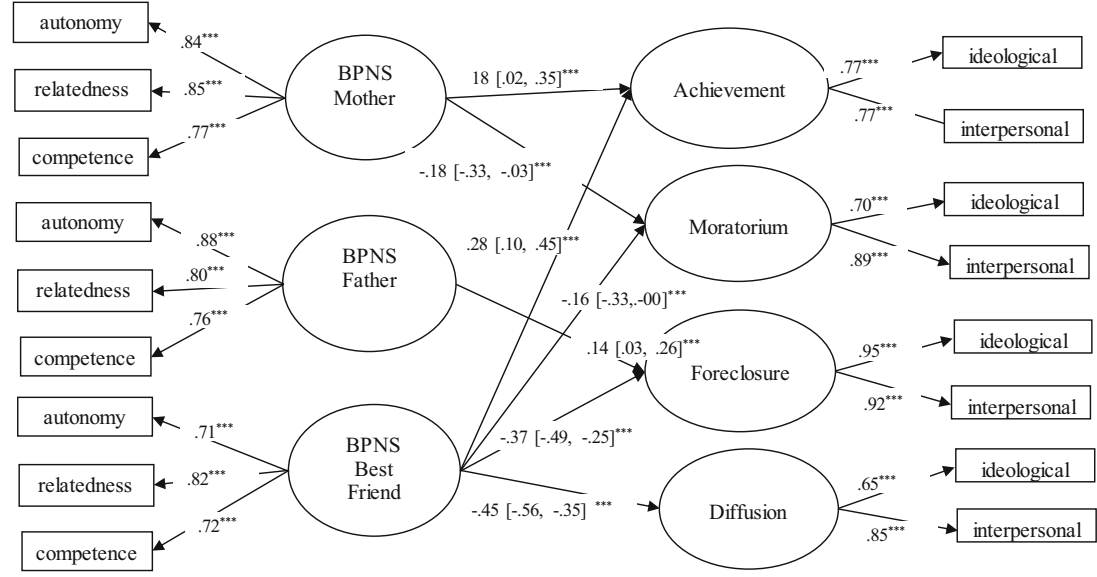

M Plus 7.4 (Muthén and Muthén 1998-2015; see Figs. 2, 3 and 4). Participants' age, sex, and SES were included in the model as the control variables. SEM model for mother yielded good fit between the data and the model: $\chi^{2}=82.17, d f=47$, $p<.01, \chi^{2} / d f=1.74$, RMSEA $=.04[.03-.06]$, CFI $/$ $\mathrm{TLI}=.98 / .97$. The examination of path coefficients indicated that only competence was significantly linked with identity statuses: Competence was positively linked with identity achievement and negatively linked with foreclosure, moratorium and identity diffusion. SEM model for the relationship with father also provided a good fit: $\chi^{2}=69.79, d f=39$, $p=.001, \chi^{2} / d f=1.79$, RMSEA $=.05[.03-.06]$, CFI $/$ $\mathrm{TLI}=.98 / .97$. Just like in the SEM model for mother, competence was positively linked with identity achievement, and negatively linked with the rest of the three identity statuses. In the father model, relatedness was positively linked with foreclosure. Finally, SEM model for the relationship with the best friend also yielded a good fit: $\chi^{2}=81.26, d f=45, p<.001$, $\chi^{2} / d f=1.80$, RMSEA $=.05$ [.03-.06], CFI $/$ TLI $=.98 / .96$. Similar to the SEM models for mother and father, competence was linked positively with identity achievement, and negatively with the rest of the identity statuses. Additionally, in the model for best friend, autonomy was positively linked with identity achievement, and relatedness was negatively linked with identity diffusion.

\section{Discussion}

The present study 1) compared the extent to which emerging adults perceived BPNS in their three important close relationships, mother, father, and best friend; 2) the links between overall BPNS perceived in the three relationship and identity statuses; and 3) the links between each basic need (autonomy, relatedness, and competence) and identity statuses in each close relationship.

Overall, the comparisons of emerging adult's perceptions of BPNS in three close relationships (research aim 1) indicated that participants perceive their relationship with their mother
Fig. 2 Links between autonomy, relatedness, and competence in the relationship with mother and identity statuses

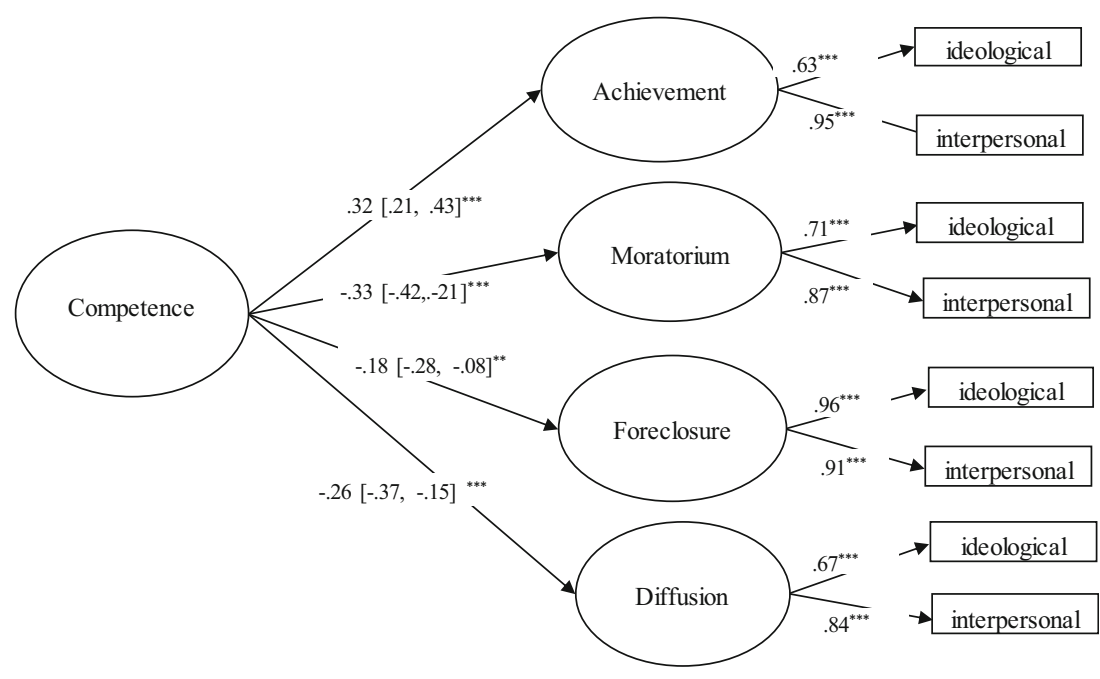


Fig. 3 Links between autonomy, relatedness, and competence in the relationship with father and identity statuses

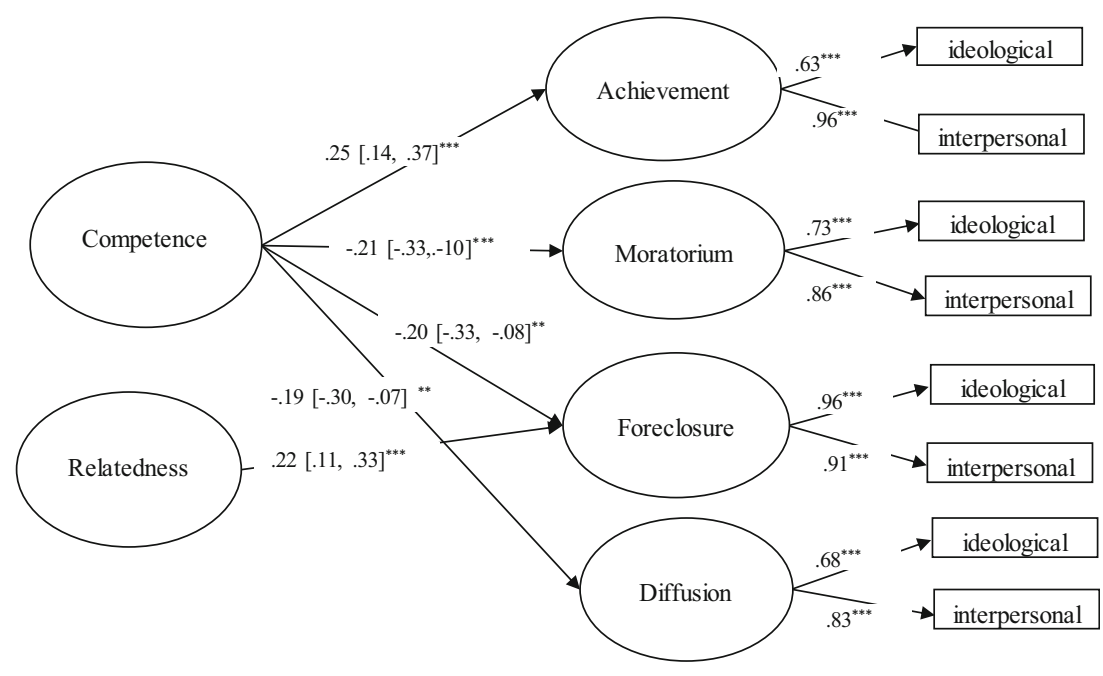

as more supportive than their relationship with their father. Similarly, relationship with best friend was found to be more supportive than the relationship with father.

The SEM analyses examining the links between BPNS in three relationships and identity statuses (research aim 2) showed that BPNS in the relationship with one's best friend was linked with all of the identity statuses: Higher BPNS in the participants' relationship with their best friend was linked with higher identity achievement and lower moratorium, foreclosure and identity diffusion. BPNS in the relationship with one's mother had significant links to two identity statuses: Higher BPNS in the relationship with one's mother was linked to higher identity achievement and lower moratorium. BPNS in the relationship with one's father had links to only one of the identity statuses: Contrary to the expectation of Hypothesis 2, BPNS with father was positively linked with foreclosure. Identity achievement includes exploration of different identity options followed by committing to the most suitable one. Moratorium involves exploration of various identity options without any commitment. Foreclosure is commitment to an identity available to the individual without any exploration. And, identity diffusion does neither involve a search for an identity nor commitment to any identity options (Marcia 1966).

SEM analyses which examined the links between each basic psychological need (autonomy, competence, and relatedness) and identity statuses in each relationship separately (i.e., mother, father, and the best friend) (research aim 3) indicated that satisfaction of competence need was positively linked with identity achievement, and negatively linked with moratorium, foreclosure, and identity diffusion across the three relationship. Additionally, in the best friend model, there was an inverse relationship between relatedness and identity diffusion, and a positive link between autonomy and identity achievement. In the father model, relatedness was positively linked with foreclosure. In the mother model, only
Fig. 4 Links between autonomy, relatedness, and competence in the telationship with best friend and identity statuses

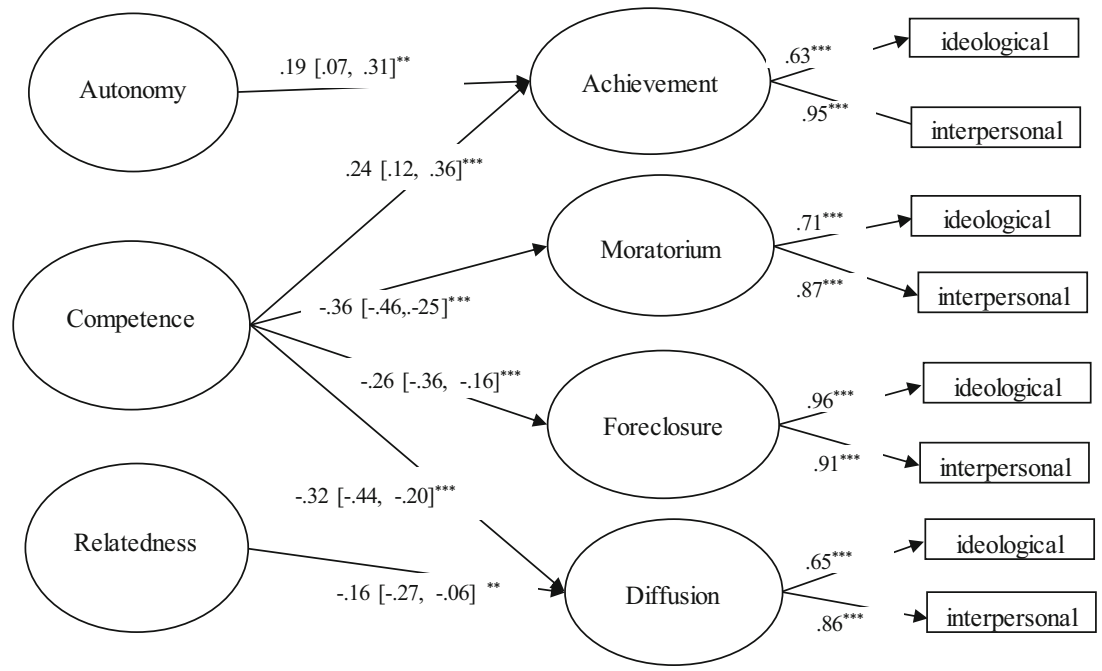


competence was a significant predictor of identity statuses. The findings were discussed below in view of the theory and literature.

\section{Differences in BPNS Across the Relationships}

The finding showing that the best friends were perceived as more supportive of basic psychological needs than either the mothers or the fathers confirmed our expectations and is congruent with the existing literature (La Guardia et al. 2000; Ryan et al. 2005). These results can be explained from the perspective of SDT and the theoretical and empirical literature (which underscores the importance of friendships in adolescence and the emerging adulthood years). According to SDT, human beings require three basic psychological needs to be met across all ages and in all relationship-based contexts (e.g., school, work, family, and close relationships) (La Guardia and Ryan 2002; Ryan and Deci 2000, 2017). The basic need of autonomy involves being able to make one's own decisions volitionally and direct one's life in accordance with one's values. Relatedness is the need to be in supportive and caring relationships, and competence is the need to feel efficient and able in the tasks a person involves in. According to SDT, these basic needs are universal and fundamental for the well-being and flourishing of individuals.

It is almost a truism that friendships gain increasing importance during adolescence; it is one of the most important changes in social relationships across adolescence (Scholte and Van Aken 2008). In this period, although parents continue to be important attachment figures, there is a decrease in the percentage of adolescents who see their relationships with their parents as a safe haven (Nickerson and Nagle 2005). In adolescence, friends are important sources of social support where personal feelings and thoughts are shared and ideas are aired and discussed (De Goede et al. 2009). In the college years, more social support is perceived in the relationship with friends and romantic friends (Furman and Buhrmester 1992). A considerable amount of research showed that friendship in emerging adulthood contribute to well-being and happiness (for a review, Demir 2010; Demir and Özdemir 2010).

The developmental significance of friends during transition to adulthood is explained in an enlightening way by Muzaffer Sherif and his colleagues (Sherif and Cantril 1947; Sherif and Sherif 1956, 1965): The transition from childhood to adulthood requires redefining social relations. In rapidly changing societies, age-related transitions and the redefinition of social roles become more complex (because the process of synthesising conflicting norms and values is a demanding endeavor). Sherif and colleagues emphasize that the transition from childhood to adulthood in modern societies is also long because the acquisition of knowledge, skills, and competencies required for adult roles requires more education and experience. During this period, adolescents find themselves 'betwixt- and-between' identity options and choices. In pursuit of meaning-making out of their experiences and putting the world in a meaningful framework, adolescents turn to their peers as a reference group because they share similar concerns and problems. The adult frame of reference is not as helpful as it was before because the adult perspective does not provide them with satisfactory answers in solving their problems (Sherif and Cantril 1947).

Sherif's remarks in the 1940s on the challenges of youth's identity pursuit and their endeavour to adapt to adult roles can be said to be valid for contemporary young people (DostGözkan and Wiium in press). The long period of 'betwixt and between and betwixt', as mentioned by Sherifs (Sherif and Sherif 1965), addressed the age window of 11 to 19 years. In today's time window of adolescence and considering the notion of emerging adulthood there is a wider age range (extending from 11 to 29 years).

When the findings of the present study are interpreted in view of these remarks, it can be stated that friends are very important companions during this prolonged period of selfdiscovery. Although young people perceive enough basic psychological need-support from their parents, they perceive their relationships with their best friends as more supportive. The Sherifs' remarks (Sherif and Sherif 1965) help us to make sense of this finding: It is probable that young people share and discuss their experiences more with their best friends. It is also probable that the communication and co-evaluation of their experiences may be more realistic and meaningful because they are in the same reference group who share common problems, developmental tasks and, as well, the same generational culture. Therefore, the autonomy-support, relatedness, and competence feedback they receive from their close friends may be more appealing to young people.

The finding that the participants perceived greater BPNS in their relationships with their mother than with their father is consistent with other studies in the literature. According to Ryan et al. (2005), young people feel closer to their mothers because they perceive more BPNS than their fathers. Relationship with one's mother was shown to have stronger impact on well-being of their children as compared to the relationship with one's father (Demir 2010; Field et al. 1995). Research with adolescents also shows that young people spend more time with their mothers (Dubas and Gerris 2002) and share more information about themselves and their private lives with them, as compared to their fathers (DostGözkan 2016). Parents who are knowledgeable about their children's life can better guide them in coping with stress and anxiety (Almas et al. 2010; Vinik et al. 2011). Sharing information about one's private life with one's parent enables the transfer of knowledge and skills from parent to child. Sharing personal information with a responsive and supportive parent also enables the child to express and regulate negative emotions in a safe environment. In a study 
conducted with adolescents, Almas et al. (2010) found that participants who talked more about their experiences with their parents displayed more competence in identifying and expressing their emotions, as well as regulating their negative emotions, than adolescents who disclosed less about themselves.

In the current study, it was found that their female participants perceived their relationships with their mothers as more supportive of basic psychological needs than did the males. Moreover, the female participants perceived their close friendship as more supportive of basic psychological needs than did the male participants. These findings are consistent with the gender-related literature. Studies examining gender differences in friendships (e.g., Helgeson 2009) have found that women's close friendships have more empathy, support, and disclosure than those of men; further, women expressed more satisfaction with their close friendships than did men.

The present study found that female participants perceived their relationship with their close friend as more supportive of their basic psychological needs than their relationship with their mothers. There was not such a difference found in the male participants' perceptions. This may be due to the fact that females' relationships with their close friends include more intimacy than those of men (and thus are found to be more supportive than their relationships with their mothers).

\section{The Links Between Gratification of Basic Psychological Needs and Identity Statuses}

The SEM analysis which simultaneously investigated the links between BPNS perceived in the three close relationships and identity statuses confirmed our expectations to some extent. From a theoretical perspective, one would expect all paths to be significant. Indeed, this was the case in correlational analyses (except that foreclosure was not lnked with BPNS with mother and father). But as Demir (2010) stated simultaneous examination of multiple relationship contexts gives information as to which relationship context is more influential when examined together with the other ones. Below each finding will be discussed in view of the literature.

BPNSs in the participants' relationships with their mother and their best friend were positively linked to identity achievement. As SDT (Ryan and Deci 2000) posits, meeting basic psychological needs in close social environments may encourage and help individuals to explore identity options, thereby increasing the likelihood that individuals will recognise and adopt the identities appropriate to them.

The link between BPNS in the relationship with mother and best friend and moratorium was negative. Theoretically this was an unexpected relationship. However, it provides support for some of the criticisms directed at the theory (which classifies moratorium as a mature and positive status of identity). In the classical taxonomy of identity statuses (e.g.,
Kroger 2007), moratorium together with achievement have been regarded as healthy identity statuses because they involve an exploration process. The foreclosure and identity diffusion statuses, on the other hand, have been regarded as problematic statuses because they either involve commitment without exploration (foreclosure) or no exploration or commitment at all (diffusion). Recent findings have challenged the assumption that exploration per se is a healthy process in the pursuit of identity. For example, Luyckx et al. (2008) showed that exploration may turn out to be a circular search for options characterised by anxiety - what they termed 'ruminative exploration'. These authors identified and empirically validated three exploration dimensions ('exploration in-breath', 'exploration in-depth', and 'ruminative exploration') and two commitment dimensions ('commitment making' and 'identification with commitment'). The scale based on this conceptualisation was validated in Turkish (Morsünbül and Çok 2014) and it has been found that all dimensions, including that of ruminative exploration, are applicable in the Turkish context. The present findings on moratorium may pinpoint a process tapped by ruminative exploration.

The positive or negative attributions to the exploration process as well as the delay in commitment to adult roles may be related to the cultural definitions of developmental acquisitions and the timeline for such acquisitions to occur. The 'social clock' a society imposes for its young members will determine the age window within which exploration of new identities can be supported and, as well, the age at which further exploration without commitment is no longer approved. For example, in a study with Japanese adolescents and emerging adults, moratorium was found to be positively associated with healthy development during adolescence but with problem behaviours during emerging adulthood (Hatano et al. 2016). Researchers stated that, unlike Western societies, in Japanese culture a decline in moratorium and an increase in identity achievement is expected.

Similar developmental expectations may be valid for the Turkish emerging adults. Future studies may examine the relationship between young people's perception of social clock, their identity status, and well-being. The inverse relationships between BNPG in the relationships with mother and best friend and moratorium might be indicating issues in finalising the exploration process with commitment. Future studies might consider examining the phenomenological experience of moratorium in the pursuit of identity in the Turkish and similar cultural contexts.

The positive link between BPNS in the relationships with father and foreclosure was theoretically unexpected. This relationship may be due to the authority role the father has within the family. According to role theory (Hosley and Montemayor 1997), the mother's role as a parent has been defined more as a caregiver and provider of warmth for her 
children, whereas fathers are traditionally expected to be the provider and disciplinarian. Indeed, it has been reported in the literature (e.g., Côté and Levine 1983) that foreclosure is associated with a higher level of authoritarianism.

The idea that foreclosure is a negative form of identity status has been criticised by researchers claiming that there may be cross-cultural differences in the way exploration and commitment is experienced in identity formation. For example, Bosma and Kunnen (2001) state that foreclosure can be a positive experience in cultures in which intergenerational ties and family harmony are valued. Cheng and Berman (2012) also state that in non-Western cultures, foreclosure might involve the process of acceptance and internalisation of the recommendations of respected authority figures. Indeed, the finding of the SEM analysis which examines the links between each psychological need and identity statuses yielded a finding which supports this interpretation: Relatedness support in the relationship with father was positively linked with foreclosure. Future studies might further test whether and under what conditions foreclosure is and is not a healthy form of identity.

The examination of the links between each need (i.e., autonomy, relatedness, and competence) and identity statuses in each close relationship (i.e., mother, father, and the best friend) yielded novel and insightful findings: It was linked to all identity statuses across all relationships. The results highlighted the importance of competence need gratification across the three relationships. As expected by SDT competence feedback was positively linked with identity achievement and negatively linked with foreclosure and identity diffusion. The negative link between competence and moratorium was unexpected, but as explained above for the negative link between BPGN and moratorium, this specific finding highlights that moratorium may not be a positive experience in the Turkish context. The SEM analyses conducted for the best friend yielded additional significant links underscoring the importance of the developmental importance of friendship during emerging adulthood: Autonomy was positively linked with identity achievement, and relatedness was negatively linked with identity diffusion. Autonomy was not a significant predictor in the model for mother and father. The autonomy support from the best friend may have a different meaning for a young person who is in pursuit of identity again for the reason Sherif articulated decades ago (Sherif and Sherif 1956): Friendships are important for the young as they are grappling with similar problems. They share and understand each other's concerns, challenges they face and hence befriend each other as they navigate through a variety of developmental tasks. Finally, relatedness support from the best friend was negatively linked with identity diffusion indicating that relatedness from the best friend may provide support and buffer against setbacks and lack thereof may be potentially count as a lack of social resource in the pursuits of identity.

\section{Conclusion}

It has been stated that in the literature that examining multiple relationships multiple close relationships is a helpful approach to understand their relative contribution to the outcome variables (Demir 2010). The present research contributed to the literature by 1) examining the relative significance of three important close relationships for emerging adults in perceived satisfaction of basic psychological needs 2) simultaneously examining the links between BPNS in three important close relationships and identity statuses and 3) examining the links between each basic psychological need and identity statuses in each relationship.

In a nutshell, the findings underscored the importance of close friends as social supports in the pursuit of identity in emerging adulthood. Results also underlined the satisfaction of need for competence as a facilitator in the pursuit identity. It was astonishing that competence was linked with all of the identity statuses across the three relationships. This finding has significant implications for social policies that can aim to facilitate and support healthy pursuit of identity during emerging adulthood. Future research may examine if the salience of need for competence is developmentally more relevant in emerging adulthood, and which need would be the more salient for the pursuit of identity in adolescence.

This study also has some limitations: The results are from cross-sectional data and cannot support causal explanations. The present sample consisted only of college students, as the characteristics of emerging adulthood have been shown to exist only in those persons receiving education at the college level (as opposed to young people of the same age who are not in the education system in the Turkish context) (Morsünbül 2013). Future studies might consider examining the identity pursuits of young people who do not show the characteristics of emerging adulthood.

\section{Compliance with ethical standards}

Conflict of interest On behalf of all authors, the corresponding author states that there is no conflict of interest.

Ethical procedures All procedures performed in the study which involved human participants were in accordance with the ethical standards of the institutional and/or national research committee and with the 1964 Helsinki declaration and its later amendments or comparable ethical standards. The ethics approval was obtained from The Board of Research Ethics at Ozyegin University. 
Both authors are equally involved in the design, data collection, analyses, and writing of the manuscript.

Data is available upon reasonable request from the authors.

\section{References}

Ahmed, H. S. (2019). Religious identity development in emerging adulthood. Master Thesis, Ankara University.

Almas, A. N., Grusec, J., \& Tackett, J. L. (2010). Children's disclosure and secrecy: Links to maternal parenting characteristics and children's coping skills. Social Development, 3, 624-643.

Amato, P. (1994). Father-child relations, mother-child relations, and offspring psychological well-being in early adulthood. Journal of Marriage and Family, 56, 1031-1042.

Aquilino, W. S. (1997). From Adolescent to Young Adult: A Prospective Study of Parent-Child Relations during the Transition to Adulthood. Journal of Marriage and the Family 59(3):670

Aquilino, W. S. (2006). Family relationships and support Systems in Emerging Adulthood. In J. J. Arnett \& J. L. Tanner (Eds.), Emerging adults in America: Coming of age in the 21st century (p. 193-217). American Psychological Association.

Arnett, J. J. (2000). Emerging adulthood: A theory of development from the late teens through the twenties. American Psychologist, 55, 469480.

Arnett, J. J. (2004). Emerging adulthood: The winding road from the late teens through the twenties. New York: Oxford University Press.

Arnett, J. J., Žukauskienè, R., \& Sugimura, K. (2014). The new life stage of emerging adulthood at ages 18-29 years: Implications for mental health. The Lancet Psychiatry, 1, 569-576.

Atak, H. (2005). Beliren yetiskinlik: Yeni bir yasam döneminin Türkiye'de incelenmesi. MA thesis. Ankara Üniversitesi, Ankara.

Atak, H. (2011). Kimlik gelişimi ve kimlik biçimlenmesi: Kuramsal bir değerlendirme. Psikiyatride Güncel Yaklaşımlar, 3, 163-213.

Atak, H., \& Çok, F. (2008). The Turkish version of inventory of the dimensions of emerging adulthood (the IDEA). International Journal of Human and Social Sciences, 2, 721-727.

Atak, H., \& Taştan, N. (2012). Agency in the emerging adulthood period: An introductory study in Turkey. European Journal of Social Sciences, 32, 97-107.

Atak, H., Kapçı, E. G., \& Çok, F. (2012). Yetişkinliğe geçişte bireyselleșme türleri ve kimlik statüleri: Üniversite öğrencileri ve unutulan yarı. Klinik Psikiyatri, 16, 71-82.

Barry, C. M., Padilla-Walker, L. M., \& Nelson, L. J. (2012). The role of mothers and media on emerging adults' religious faith and practices by way of internalization of prosocial values. Journal of Adult Development, 19, 66-78.

Barry, C. M., Padilla-Walker, L. M., Madsen, S. D., \& Nelson, L. J. (2008). The impact of maternal relationship quality on emerging adults' prosocial tendencies: Indirect effects via regulation of prosocial values. Journal of Youth and Adolescence, 37, 581-591.

Barry, C. M., Madsen, S. D., \& DeGrace, A. (2016). Growing up with a little help from their friends in emerging adulthood. In J. J. Arnett (Ed.), Oxford library of psychology. The Oxford handbook of emerging adulthood (p. 215-229). Oxford University Press.

Bennion, L. D., \& Adams, G. R. (1986). A revision of the extended version of objective measure of Ego identity status: An identity instrument for use with late adolescents. Journal of Adolescent Research, 1, 183-198.

Berzonsky, M. D., \& Adams, G. R. (1999). Reevaluating the identity status paradigm: Still useful after 35 years. Developmental Review, $19,557-590$.
Bosma, H. A., \& Kunnen, E. S. (2001). Determinants and mechanisms in ego identity development: A review and synthesis. Developmental Review, 21, 39-66.

Cheng, M., \& Berman, S. L. (2012). Globalization and identity development: A Chinese perspective. In S. J. Schwartz (Ed.), Identity around the world. New Directions for Child and Adolescent Development, 138, 103-121.

Crocetti, E., Cieciuch, J., Gao, C.-H., Klimstra, T., Lin, C.-L., Matos, P. M., et al. (2015). National and gender measurement invariance of the Utrecht-Management of Identity Commitments Scale (UMICS): A 10-nation study with university students. Assessment, 22, 753-768.

Crocetti, E., Rubini, M., \& Meeus, W. (2008). Capturing the dynamics of identity formation in various ethnic groups: Development and validation of a three-dimensional model. Journal of Adolescence, 31, 207-222.

Côté, J. E. (2006). Emerging adulthood as an institutionalized moratorium: Risks and benefits to identity formation. In J. J. Arnett \& J. L. Tanner (Eds.), Emerging adults in America: Coming of age in the 21st century (pp. 85-116). Washington, DC: American Psychological Association.

Côté, J. (2009). Identity formation and self-development in adolescence. In R. M. Lerner \& L. Steinberg (Eds.), Handbook of adolescent psychology (Vol. 1, pp. 266-304). Hoboken: Wiley.

Côté, J. E., \& Levine, C. (1983). Marcia and Erikson: The relationships among ego identity status, neuroticism, dogmatism, and purpose in life. Journal of Youth and Adolescence, 12, 43-53.

Deci, E. L., \& Ryan, R. M. (2000). The darker and brighter sides of human existence: Basic psychological needs as a unifying concept. Psychological Inquiry, 11, 319-338.

Deci, E. L., Ryan, R. M., Gagné, M., Leone, D. R., Usunov, J., \& Kornazheva, B. P. (2001). Need satisfaction, motivation, and wellbeing in the work organizations of a former Eastern Bloc country: A cross-cultural study of self-determination. Personality and Social Psychology Bulletin, 27, 930-942.

Deci, E. L., La Guardia, J. G., Moller, A. C., Scheiner, M. J., \& Ryan, R. M. (2006). On the benefits of giving as well as receiving autonomy support: Mutuality in close friendships. Society of Personality and Social Psychology, 32, 313-327.

De Goede, I. H. A., Branje, S. J. T., Meeus, W. H. J. (2009) Developmental changes and gender differences in adolescents' perceptions of friendships. Journal of Adolescence 32 (5):1105-1123

Demir, M. (2010). Close relationships and happiness among emerging adults. Journal of Happiness Studies, 11, 293-313.

Demir, M., \& Özdemir, M. (2010). Friendship, need satisfaction and happiness. Journal of Happiness Studies, 11, 243-259.

Demir, M., Özdemir, M., \& Weitekamp, L. A. (2007). Looking to happy tomorrows with friends: Best and close friendships as they predict happiness. Journal of Happiness Studies, 8, 243-271.

Dost-Gözkan, A. (2015). An integration of social and developmental psychology: Sherif's works with adolescence (pp. 345-364). In A. Dost-Gözkan \& D. Sönmez (Eds.), J. Valsiner (series Ed.). Norms, groups, conflict, and social change: Rediscovering Muzafer Sherif's psychology. New Brunswick, NJ: Transaction Publishers.

Dost-Gözkan, A. (2016). Adolescent disclosure and secrecy in different relationship contexts and psychological well-being. Paper presented at the 15th Biennial Conference of the European Association for Research on Adolescence, Cádiz, Spain.

Dost-Gözkan, A., \& Wiium, N. (in press). Developmental assets and identity among emerging adults in Turkey. In R. Dimitrova \& N. Wiium (Eds.), Handbook of positive youth development. New York: Springer. 
Dubas, J. S., \& Gerris, J. R. M. (2002). Longitudinal changes in the time parents spend in activities with their adolescent children as a function of child age, pubertal status, and gender. Journal of Family Psychology, 16, 415-427.

Ergin, E. (2015). The relationship between identity status and coping strategies among emerging adulthood. Master Thesis, Ufuk University, Ankara.

Erikson, E. (1956). The problem of ego identity. Journal of the American Psychoanalytic Association, 4, 56-121.

Faye, C., \& Sharpe, D. (2008). Academic motivation in university: The role of basic psychological needs and identity formation. Canadian Journal of Behavioral Science, 40, 189-199.

Field, T., Lang, C., Yando, R., \& Bendell, D. (1995). Adolescents' intimacy with parents and friends. Adolescence, 30, 133-140.

Furman, W., \& Buhrmester, D. (1992). Age and sex differences in perceptions of networks of personal relationships. Child Development, $63,103-115$.

Gilmore, G. C. (2007). Inappropriate use of covariate analysis renders meaningless results. Journal of the International Neuropsychological Society, 13, 370.

Hartup, W. W., \& Stevens, N. (1997). Friendships and adaptation in the life course. Psychological Bulletin, 121, 355-370.

Hatano, K., Sugimura, K., \& Crocetti, E. (2016). Looking at the dark and bright sides of identity formation: New insights from adolescents and emerging adults in Japan. Journal of Adolescence, 47, 156-168.

Helgeson, V. (2009). Psychology of gender. Third Edition. Upper Saddle River: Pearson.

Hosley, C., \& Montemayor, R. (1997). Fathers and adolescents. In M. Lamb (Ed.), The role of the father in child development (pp. 23-45). New York: Wiley.

Ilhan, T., \& Özdemir, Y. (2012). Beliren yetişkinlerde yaş, cinsiyet ve bağlanma stillerinin kimlik statüleri üzerindeki yordayıcı rolü. Dicle Üniversitesi Ziya Gökalp Eğitim Fakültesi Dergisi, 19, 227-241.

Kroger, J. (2007). Identity development: Adolescence through adulthood. Thousand Oaks: Sage.

Kroger, J., \& Marcia, J. (2011). The identity statuses: Origins, meanings, and interpretations. In S. J. Schwartz, K. Luyckx and V. Vingoles (Eds.) (pp. 31-53), Handbook of identity theory and research (3153). London: Springer.

Kumru, A., \& Thompson, R. A. (2003). Ego identity status and selfmonitoring behavior in adolescents. Journal of Adolescent Research, 18, 481-495.

La Guardia, J. G., \& Ryan, R. M. (2002). What adolescents need: A selfdetermination theory perspective on development within families, school and society. In F. Pajares \& T. Urdan (Eds.), Academic motivation of adolescents (pp. 193-220). Greenwich: IAP.

La Guardia, J. G., Ryan, R. M., Couchman, C. E., \& Deci, E. L. (2000). Within-person variation in security of attachment: A selfdetermination theory perspective on attachment, need fulfillment, and well-being. Journal of Personality and Social Psychology, 79, 367-384.

Luyckx, K., Schwartz, S.J, Berzonsky, M., Soenens, B., Vansteekiste, M., Smith, I., \& Goossens, L. (2008). Capturing ruminative exploration: Extending the four-dimensional model of identity formation in late adolescence. Journal of Research in Personality, 42, 58-82.

Luyckx, K., Vansteenkiste, M., Goossens, L., \& Duriez, B. (2009). Basic need satisfaction and identity formation: Bridging selfdetermination theory and process-oriented identity research. Journal of Counseling Psychology, 56, 276-288.

Marcia, J. E. (1966). Development and validation of ego-identity status. Journal of Personality and Social Psychology, 3, 551-558.
Morsünbül, Ü. (2013). Are they emerging adults or emerging adults who are university students? An investigation through risk taking and identity development. Elementary Education Online, 12, 873-885.

Morsünbül, Ü., \& Çok, F. (2014). Kimlik Boyutları Ölçeğinin Türkçeye Uyarlanmas1, [Validation of Dimensions of Identity Development Scale in Turkish]. Düşünen Adam, 7, 6-14.

Morsünbül, Ü., Crocetti, E., Çok, F., \& Meeus, W. (2015). Identity statuses and psychosocial functioning in Turkish youth: Personcentered approach. Journal of Adolescence, 47, 145-155.

Muthén, L. K., \& Muthén, B. O. (1998-2015). Mplus User's Guide. Los Angeles: Muthén\& Muthén.

Nauck, B., \& Klaus, D. (2008). Family change in Turkey: Peasant society, Islam and the revolution "from above". In R. Jayakody, A. Thornton, \& W. Axinn (Eds.), International family change: Ideational perspectives (pp. 281-312). New York: Lawrence Erlbaum.

Nickerson, A. B., \& Nagle, J. N. (2005). Parent and peer attachment in late childhood and early adolescence. Journal of Early Adolescence, 25, 223-249.

Oskay, G. (1998). Adaptation of extended objective measure of measure of Ego identity status into Turkish. Psikolojik Danışma ve Rehberlik Dergisi, 2, 17-24.

Padilla-Walker, L., Memmott-Elison, K. M., \& Nelson, J. L. (2017). Positive relationships as an indicator of flourishing in emerging adulthood. In L. Padilla-Walker \& J. L. Nelson (Eds.), Flourishing in emerging adulthood: Positive development during the third decade of life (pp. 212-236). New York: Oxford University Press.

Ryan, R. M., \& Deci, E. L. (2000). Self-determination theory and the facilitation of intrinsic motivation, social development, and wellbeing. American Psychologist, 55, 68-78.

Ryan, R. M., \& Deci, E. L. (2003). On assimilating identities to the self: A self-determination theory perspective on internalization and integrity within cultures. In M. R. Leary \& J. P. Tangney (Eds.), Handbook on self \& identity (pp. 253-274). New York: The Guilford Press.

Ryan, R. M., \& Deci, E. L. (2017). Self-determination theory: Basic psychological needs in motivation, development, and wellness. New York: Guilford Press.

Ryan, R. M., La Guardia, J. G., Solky-Butzel, J., Chirkov, V., \& Kim, Y. (2005). On the interpersonal regulation of emotions: Emotional reliance across gender, relationships, and cultures. Personal Relationships, 12, 145-163.

Scholte, R. H. J., \& Van Aken, M. A. G. (2008). Peer relations. In S. Jackson \& L. Goossens (Eds.), Handbook of adolescent development (pp. 175-197). Hove: Psychology Press.

Schwartz, S. J., Zamboanga, B. L., Luyckx, K., Meca, A., \& Rithcie, R. A. (2013). Identity in emerging adulthood: Reviewing the field and looking forward. Emerging Adulthood, 1, 96-113.

Sherif, M., \& Cantril, H. (1947). The psychology of ego-involvements: Social attitudes and identifications. New York: Wiley \& Sons.

Sherif, M., \& Sherif, C. W. (1956). An outline of social psychology (revised ed.). New York: Harper.

Sherif, M., \& Sherif, C. W. (1965). Problems of youth: Transition to adulthood in a changing world. Chicago: Aldine Publishing Company.

Vinik, J., Almas, A., \& Grusec, J. (2011). Mothers' knowledge of what distresses and what comforts their children predicts children's coping, empathy, and prosocial behavior. Parenting: Science and Practice, 11, 56-71.

Publisher's note Springer Nature remains neutral with regard to jurisdictional claims in published maps and institutional affiliations. 